\title{
Feeding fennel (Foeniculum vulgare) seed as a potential appetite stimulant for Holstein dairy calves: Effects on growth performance and health
}

\author{
F. Nowroozinia, ${ }^{1} \odot$ S. Kargar, ${ }^{1 *} \oplus$ A. Akhlaghi, ${ }^{1} \odot$ F. Raouf Fard, ${ }^{2} \oplus$ M. Bahadori-Moghaddam, ${ }^{1}{ }^{\oplus}$ M. Kanani, ${ }^{1}{ }^{\oplus}$ \\ and M. J. Zamiri ${ }^{1}$ (1) \\ ${ }^{1}$ Department of Animal Science, School of Agriculture, Shiraz University, Shiraz 71441-65186, Iran \\ ${ }^{2}$ Department of Horticultural Sciences, School of Agriculture, Shiraz University, Shiraz 71441-65186, Iran
}

\section{ABSTRACT}

This experiment was conducted to determine the effect of increasing dietary doses of fennel seed powder (FSP) on growth performance and health status in calves. Holstein calves $(\mathrm{n}=48 ; 3 \mathrm{~d}$ of age; 36.3 $\pm 1.06 \mathrm{~kg} \mathrm{BW}$; mean $\pm \mathrm{SE}$ ) were allocated randomly to diets containing 0 (FSP0), 1.5 (FSP1.5), or $3 \mathrm{~g} / \mathrm{d}$ (FSP3) FSP in milk (morning feeding; during the first month) and then in the starter feed (top-dressed; from d 31 until weaning on $d$ 71). The calves remained in the trial until d 81. Weight gain and final $\mathrm{BW}$ were greater in FSP-supplemented calves compared with control calves. Heart girth and hip width gained more in FSP-supplemented calves compared with control calves. Body weight gain and frame growth were not affected by calf sex. The calves receiving FSP had a lower chance of having elevated rectal temperature $\left(\geq 39.4^{\circ} \mathrm{C}\right)$ and a lower probability of suffering from diarrhea or pneumonia. The chance of having diarrhea, but not pneumonia, was greater in female calves. The chance of medication occurrence for diarrhea and pneumonia was not affected by FSP and calf sex. The FSP3 calves had shorter days with elevated rectal temperature $\left(\geq 39.4^{\circ} \mathrm{C}\right)$ compared with the FSP1.5 $(1.2 \mathrm{~d} ; \mathrm{SEM}=0.10)$ and FSP0 $(2.9 \mathrm{~d} ; \mathrm{SEM}=0.10)$ calves. Days with diarrhea but not its frequency and medication days was shorter $(4 \mathrm{~d}$; SEM $=0.10)$ in the FSP-supplemented calves. Control calves experienced more days with pneumonia compared with calves fed FSP1.5 (3.1 d; SEM = 0.08) and FSP3 (5.4 d; SEM = 0.08). Calves fed FSP3 experienced shorter days ( $2.3 \mathrm{~d}$; $\mathrm{SEM}=0.08)$ with pneumonia compared with calves fed FSP1.5. Feeding FSP tended to decrease (1.6 d; SEM $=0.10)$ medication days for pneumonia compared with control group. The duration $(2.2 \mathrm{~d} ; \mathrm{SEM}=0.10)$ and medication days $(1.3 \mathrm{~d}$; SEM $=0.15)$ for diarrhea were

Received January 26, 2021.

Accepted October 4, 2021.

*Corresponding author: skargar@shirazu.ac.ir higher in female calves compared with the male calves. Compared with the control calves, feeding $3 \mathrm{~g} / \mathrm{d}$ of FSP may be more beneficial in improving the weight gain and skeletal growth (heart girth and hip width) and in reducing the susceptibility to and duration of diarrhea and pneumonia in dairy calves.

Key words: aroma, heifer raising, herbal plant, wellbeing

\section{INTRODUCTION}

Preweaning calves are predisposed to digestive and respiratory disturbances that are costly to treat and may also cause early mortality. A survey conducted by the USDA (2016) reported that $33.8 \%$ of female dairy calves had experienced at least one morbidity event with $5 \%$ mortality rate before weaning. Urie et al. (2018) reported that in the United States, of all the deaths in preweaning dairy heifer calves, 32.0 and $14.1 \%$ were due to digestive and respiratory disturbances, respectively. In a study by Urie et al. (2018), majority of suffered calves showed digestive $(56 \%)$ or respiratory $(33.4 \%)$ signs. In the United States and Canada, 4.2 to $9.6 \%$ of male dairy calves die on veal farms (Pempek et al., 2017; Renaud et al., 2018). Between 25 and $87 \%$ of calves are treated at least once for disease in Belgium (Pardon et al., 2012) and Canada (Scott et al., 2019). Still, preweaning morbidity and mortality rates are above the Dairy Calf and Heifer Association (2010) target rates of less than 25 and $5 \%$, respectively. Therefore, there is a need to further attenuate the overall morbidity and mortality in dairy calves before weaning.

Conventional antibiotics, added to liquid or starter feeds, have been used to decrease the morbidity and mortality, and to increase the feed intake and growth in calves; however, the use of such antibiotics in animalagriculture has been criticized in terms of the emerging public health crisis due to antibiotic resistance (Hajalizadeh et al., 2019). Therefore, there has been growing interests in the use of herbal plants such as fennel (Foeniculum vulgare) as alternatives to conven- 
tional antibiotics in promoting the growth and health of young animals (Saeedi et al., 2017; Hajalizadeh et al., 2019; Kargar et al., 2021). It has also been used for prevention or treatment of the digestive and respiratory diseases (Badgujar et al., 2014; Kooti et al., 2015). Fennel aroma is due to its essential oils; mainly trans-anethole, fenchone, limonene, and estragole (Kargar et al., 2021). Fennel also contains other bioactive compounds with estrogenic (due to dianethole and photoanethole as derivatives of trans-anethole), antimicrobial (due to oleic acid, linoleic acid, 1,3-benzenediol, undecanal, 2,4-undecadienal, and 5-hydroxy-furanocoumarin), antioxidant and anti-inflammatory (due to essential oils, flavonoids, phenolic acids, hydroxycinnamic acids, coumarin, and tannin), antianxiety, antiseptic, antiulcer, analgesic, carminative, antispasmodic, and expectorant properties (Badgujar et al., 2014).

The antioxidants in fennel decrease the mucosal lining of stomach, abdominal pain, gastric ulcer, and spastic gut disturbances by inhibiting the acetylcholine and histamine-induced contractions (Badgujar et al., 2014; Kooti et al., 2015). Fennel essential oil regulates the intestinal smooth muscle motility, thereby reducing the gastrointestinal gas production (Kooti et al., 2015). It also stimulates the ciliary motility in the respiratory system and increases the external transport of extraneous corpuscles which help medicating the bronchial and bronchopulmonary dysplasia, especially in the polluted environments (Badgujar et al., 2014). Essential oil also stimulates the contraction of the tracheal smooth muscle, an action that could facilitate the expectoration of mucus, bacteria, and other corpuscles extraneous to the respiratory tracts (Badgujar et al., 2014).

Beneficial effect of feeding fennel seed powder (FSP) has been reported in several livestock studies. Dietary inclusion of FSP $(3.2 \%)$ increased the feed intake (5.6\%) and BW gain $(4.7 \%)$ in heat-stressed broilers with no effect on feed efficiency (Al-Sagan et al., 2020). Feeding FSP $(10 \mathrm{~g} / \mathrm{d})$ to Mohabadi dairy goats from $30-\mathrm{d}$ before to 30 -d after kidding increased the feed intake during the pre- and postpartum periods, enhanced weight gain before kidding, reduced BW loss after kidding, and increased milk and milk composition yields as well as feed efficiency (Yari-Haj-Atalou et al., 2017). Hajalizadeh et al. (2019) reported that adding FSP (1.5\%) to the fattening diet of Kermani lambs increased the feed intake, feed efficiency, and weight gain. Adding FSP $(0.4 \%)$ to the starter diet of Holstein dairy calves improved the feed intake, feed efficiency, and growth performance and decreased the weaning age (Saeedi et al., 2016 and 2017). The increase in feed intake and weight gain due to feeding fennel seeds to calves, is important for rumen development, smoother transition from liquid- to solid-feeding stages, and maintaining the weight gain (Kargar and Kanani, 2019). However, the association between fennel seed containing feeds and growth in conjunction with health-related criteria has not been studied extensively. Therefore, the purpose of this study was to examine the growth performance and health-related variables in dairy calves fed fennel seeds before weaning in a dose response trial $(0,1.5$, and $3 \mathrm{~g} / \mathrm{d}$ ). We hypothesized that supplementing the milk and starter feed with FSP would increase BW gain and improve health status in dairy calves.

\section{MATERIALS AND METHODS}

The experiment was conducted from November 30, 2019, to February 20, 2020, at the Pegah-e-Fars Agriculture and Animal Husbandry Farm, Shiraz, Iran. All procedures were approved by the Animal Care and Use Committee of Shiraz University (Shiraz, Iran; IACUC \# 9731917) as suggested by the Iranian Council of Animal Care (1995).

\section{Environment, Animals, Treatments, and Management}

Air temperature $\left({ }^{\circ} \mathrm{C}\right)$ and relative humidity $(\%)$ in the calf barn were recorded daily (model HTC-1; Temperature Humidity Meter, Xuzhou Sanhe Automatic Control Equipment Co., Ltd.), and temperature-humidity index was calculated according to NRC (2001) as shown in Figure 1. The average climatological values were $15.8 \pm 6.2$ (maximum $\pm \mathrm{SD}$ ), $9.4 \pm 3.7$ (mean \pm $\mathrm{SD}$ ), and $2.9 \pm 2.8^{\circ} \mathrm{C}$ (minimum $\pm \mathrm{SD}$ ), respectively, for temperature, $59.5 \pm 12.2,49.2 \pm 11.3$, and 39.0 \pm 14.4 for relative humidity, and $58.8 \pm 6.4,51.6 \pm$ 4.5 , and $44.3 \pm 3.5$ for temperature-humidity index throughout the experiment.

Several criteria were used for inclusion of the calves in the study. The calf vigor was assessed by the herd veterinarian using the vigor scoring system (MurrayKerr et al., 2018). Calves with good (score 21-22) or higher vigor [very good (score 23-25) or excellent (score 26-27)] scores, 30 to $40 \mathrm{~kg}$ birth weight, and blood total protein level $\geq 5.5 \mathrm{mg} / \mathrm{dL}$ were selected for the experiment. Calves with diarrhea, fever, physical disabilities, failure of suckling, and other health-related problems were not enrolled in the study. Healthy newborn calves were balanced for BW, blood total protein, sex, and dam parity, and then allocated to individual pens (6 calves daily; 2 calves/treatment per day) during the 8 succeeding days. Forty-eight (27 males and 21 females) calves $(\mathrm{n}=16$ per treatment; $3 \mathrm{~d}$ of age; $\mathrm{BW}=36.3 \pm$ $1.06 \mathrm{~kg}$; blood total protein $=5.8 \pm 0.16 \mathrm{mg} / \mathrm{dL}$; dam parity $=2.7 \pm 0.20$; mean $\pm \mathrm{SE}$ ) were kept randomly in individual pens $(2.1 \times 1.2 \times 1.8 \mathrm{~m}$; length $\times$ width $x$ height). To maintain a sanitary housing, wheat straw 


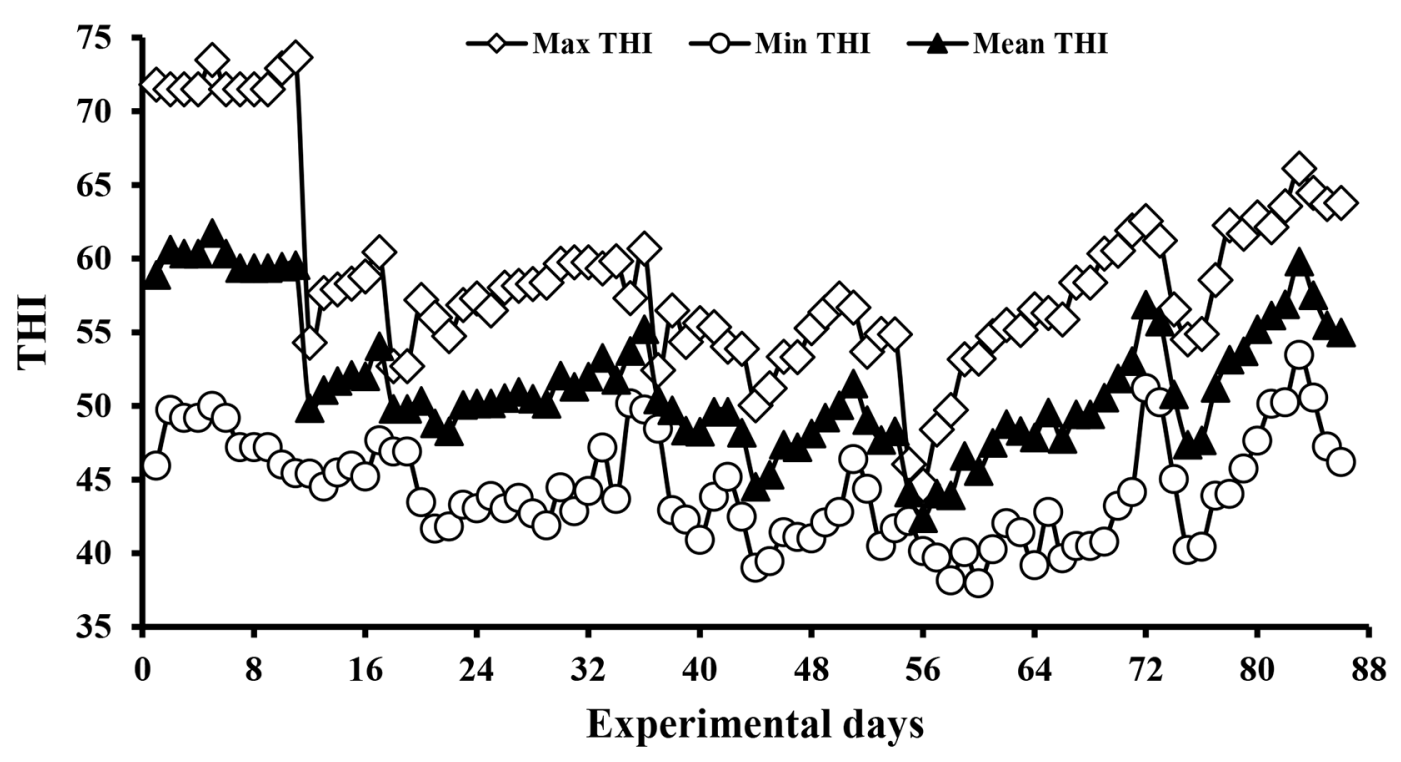

Figure 1. Temporal pattern of minimum (Min), mean, and maximum (Max) temperature-humidity index (THI) during the experiment. The average maximum THI, relative humidity, and maximum temperature were $58.8,39.0 \%$, and $15.8^{\circ} \mathrm{C}$, respectively.

bedding was replenished and manure removed on a daily basis. The calves were fed $4.5 \mathrm{~kg}$ of pasteurized $\left(60^{\circ} \mathrm{C}\right.$ for $60 \mathrm{~min}$; Model SM-392510; Shirmack Pasteurizer, Shirmack Livestock Engineering Group) colostrum (Brix value $=24.8 \pm 1.89 \%$, range: $22-28 \%$ ) within the first hour of life $(2.5 \mathrm{~kg})$ using a nipple bottle, and again $12 \mathrm{~h}$ after the first feeding $(2.0 \mathrm{~kg})$. On the second day of life, the calves were fed pasteurized transition milk $\left(60^{\circ} \mathrm{C}\right.$ for $\left.60 \mathrm{~min} ; 5 \mathrm{~kg}\right)$ in 2 meals of equal volume (at 0800 and $1800 \mathrm{~h}$ ). From d 3 onwards, the calves were individually fed with pasteurized $\left(67.5^{\circ} \mathrm{C}\right.$ for $30 \mathrm{~min}$; Model MS-3000 Pasteurizer; Sanaye Boroodati Nasr Inc.) waste milk [nonsaleable milk (temperature set at $39 \pm 1.0^{\circ} \mathrm{C}$ ) containing antibiotic or drug residues; $4.5 \mathrm{~kg} / \mathrm{d}$ from d 1-14, $5 \mathrm{~kg} / \mathrm{d}$ from d $15-23,6 \mathrm{~kg} / \mathrm{d}$ from d 24-64, and $2 \mathrm{~kg} / \mathrm{d}$ from d $65-70$ of the study; containing $11.84 \% \mathrm{DM}, 3.15 \% \mathrm{CP}$, and $3.52 \%$ crude fat on as-fed basis] in steel buckets in 3 meals of equal volume (at 0900, 1700, and $0100 \mathrm{~h}$ ). Waste milk from the farm was transported daily to a refrigerated bulk tank equipped with a blender, and offered after pasteurizing; milk refusal was not recorded.

The calves were allocated to receive FSP (ground to pass through 1-mm screen based on daily usage) in milk (morning feeding) during the first month of the experimental period and then in the starter feed diet (as top-dressed; Table 1 ) at $0,1.5$, and $3 \mathrm{~g} / \mathrm{d}$ until weaning (d 71). To ensure that each calf consumed the allocated amount of fennel seed, the FSP was mixed with $50 \mathrm{~g}$ of daily starter feed allowance and top-dressed. Calves had free access to starter feed (mashed form) and fresh water in bucket during the study. Animals were weaned on $\mathrm{d} 71$ and remained in the trial until $\mathrm{d} 81$. The person who was involved with the execution of the experiment was aware of the treatment allotment at the different

Table 1. Ingredients and chemical composition (\% DM, unless otherwise noted) of the basal starter feed diet

\begin{tabular}{lc}
\hline Item & Value \\
\hline Ingredient & \\
Alfalfa hay & 9.0 \\
Corn grain, ground & 48.3 \\
Barley grain, ground & 10.0 \\
Soybean meal & 26.3 \\
Vitamin premix ${ }^{2}$ & 1.1 \\
Mineral premix ${ }^{2}$ & 1.1 \\
Calcium carbonate & 1.1 \\
Sodium bicarbonate & 1.6 \\
Magnesium oxide & 0.5 \\
Bentonite & 0.5 \\
Salt & 0.5 \\
Chemical composition & \\
DM & 94.3 \\
CP & 20.3 \\
NFC & \\
NDF & 52.0 \\
Ether extract (EE) & 14.8 \\
Ash & 2.9 \\
Calcium & 10.0 \\
Phosphorus & 0.7 \\
ME, ${ }^{4}$ Mcal/kg of DM & 0.4 \\
NE ${ }_{\mathrm{M}}{ }^{4}$ Mcal/kg of DM & 2.95 \\
NE ${ }_{\mathrm{G}}{ }^{4}$ Mcal/kg of DM & 2.22 \\
\hline
\end{tabular}

${ }^{1}$ Contained per kilogram of the supplement: 1,500,000 IU of vitamin A, 250,000 IU of vitamin D, and 10,000 IU of vitamin E.

${ }^{2}$ Contained per kilogram of the supplement: $16 \mathrm{~g}$ of $\mathrm{Zn}, 12 \mathrm{~g}$ of $\mathrm{Mn}, 3.5$ $\mathrm{g}$ of $\mathrm{Cu}, 120 \mathrm{mg}$ of I, $120 \mathrm{mg}$ of Co, and $80 \mathrm{mg}$ of Se.

${ }^{3} \mathrm{NFC}=100-(\mathrm{CP}+\mathrm{NDF}+\mathrm{EE}+\mathrm{ash})(\mathrm{NRC}, 2001)$.

${ }^{4}$ Calculated from NRC (2001). 
stages of the study (during the allotment, execution, outcome assessment, and data analysis).

\section{Sampling and Analyses}

Samples of FSP ( $\mathrm{n}=9$; pooled within trial period), starter feed $(\mathrm{n}=9$; pooled within trial period $)$, and refusals ( $\mathrm{n}=8 /$ calf; pooled by calf within treatment) were taken immediately before the morning feeding every $10 \mathrm{~d}$ during the trial for DM and chemical measurements. A forced-air oven was used to measure the DM content of samples by drying at $100^{\circ} \mathrm{C}$ for $24 \mathrm{~h}$ (AOAC International, 2002; method 925.40). After mixing, the samples were ground to pass a 1-mm screen in a Wiley mill (Ogawa Seiki Co., Ltd.) and analyzed in triplicate for CP using the Kjeldahl method (Kjeltec 1030 Auto Analyzer, Tecator; AOAC International, 2002; method 955.04), ether extract (EE; AOAC International, 2002; method 920.39), crude ash (AOAC International, 2002; method 942.05), and NDF using a heat-stable $\alpha$-amylase $(100 \mu \mathrm{L} / 0.5 \mathrm{~g}$ of sample) and sodium sulfite (Van Soest et al., 1991). The NFC component was calculated as $100-(\mathrm{CP}+\mathrm{NDF}+\mathrm{EE}+\mathrm{Ash})(\mathrm{NRC}, 2001)$. Fennel powder contained $93 \% \mathrm{DM}, 34.7 \% \mathrm{CP}, 13.1 \% \mathrm{EE}$, and $1.0 \%$ ash.

Pasteurized pooled waste milk was sampled daily (3 samples/d; one sample at each feeding time) and preserved with potassium dichromate, stored at $4^{\circ} \mathrm{C}$, and submitted to the Central Milk Testing Laboratory of the farm to determine the DM as well as fat and protein concentrations using an infrared analyzer (MilkoScan 134 BN; Foss Electric).

Twenty-four hours after the first feeding of colostrum, jugular blood samples were collected in Vacutainer tubes (BD Vacutainer) containing spray-coated silica to quantify the serum total protein using a commercially handheld clinical refractometer (model ATA-2771; Atago Co. Ltd.). The bottom threshold $(\geq 5.5 \mathrm{mg} / \mathrm{dL})$ for passive transfer of immunoglobulins was equal in all treatment groups, and only the calves with serum total protein level $\geq 5.5 \mathrm{mg} / \mathrm{dL}$ were implemented in the study. The average $( \pm \mathrm{SE})$ serum total protein was 5.78 $\pm 0.16,5.73 \pm 0.14$, and $5.86 \pm 0.19 \mathrm{mg} / \mathrm{dL}$ in FSP0, FSP1.5, and FSP3 treatment groups, respectively.

\section{Growth}

Body weight was recorded using a calibrated electronic scale (model WLC; Etemad Co.) at birth, at the initiation ( $\mathrm{d} 1$ ) of the study, and every $10 \mathrm{~d}$ thereafter before the morning feeding, and $\mathrm{ADG}(\mathrm{g}$ of $\mathrm{BW} / \mathrm{d})$ was calculated as the difference between BW taken at 10-d intervals divided by 10 . Skeletal measurements including the heart girth (circumference of the chest), withers height (distance from base of the front feet to the withers), body length (distance between the points of shoulder and rump), hip height (distance from the base of the rear feet to hook bones), and hip width (distance between the points of hook bones) were recorded at the initiation and end of the study (Kargar et al., 2020), and the skeletal gain (d 1 to 81) was determined accordingly.

\section{Health}

During the study period (d 1-81), the calves were checked daily for the health status based on their appetite and desire to consume liquid and starter feeds, and their general appearance was checked by a veterinarian, blinded to the treatments, according to a referenced standard (Larson et al., 1977; modified by Heinrichs et al., 2003). Calves were scored daily for pneumonia using the UW Calf Health Chart (McGuirk and Peek, 2014), which assigns and sums the nasal discharge score, eye discharge score, ear tilt score, cough score, and temperature score. Although the diagnosis was not confirmed by ultrasound or nasal swab techniques, it was performed by a competent veterinarian with at least $15 \mathrm{yr}$ of experience in diagnosing and treating calf diseases to ensure correct diagnosis. Fecal score was recorded daily (before the morning feeding) for physical shape and consistency $(1=$ normal; $2=$ soft to loose; 3 = loose to watery; $4=$ watery, mucous, slightly bloody; and $5=$ watery, mucous, and bloody) while the calves were in their individual pens. Rectal temperature was recorded daily between 1300 and 1500 $\mathrm{h}$ using a digital thermometer (model MT-402; Digital Flexible Thermometer, Hangzhou Sejoy Electronics \& Instruments Co., Ltd.) placed in the rectum for approximately $1 \mathrm{~min}$. Rectal temperature was categorized as the number of days with rectal temperature $\geq 39.4^{\circ} \mathrm{C}$ (as fever threshold) and fecal score was categorized as the number of days with a fecal score $\geq 3$. These categories were denoted as days with abnormal rectal temperature and fecal score, respectively. Animals with fever, abnormal fecal score or cough were inspected by the veterinarian, unaware of the treatments, to confirm diarrhea or pneumonia diagnoses.

Animals with diarrhea (fecal score $\geq 3$ ) or pneumonia were treated following the standard procedures at the Pegah-e-Fars Agriculture and Animal Husbandry Farm (Shiraz, Iran). Calves with diarrhea received a water-based oral rehydration salt solution [containing $650 \mathrm{mg}$ of dextrose, $145 \mathrm{mg}$ of sodium chloride, $40 \mathrm{mg}$ of potassium chloride, and 165 of $\mathrm{mg}$ tri-sodium citrate per $\mathrm{g} ; 4 \mathrm{~L} / \mathrm{d}$ per calf in 2 meals of equal volume (at 1000 and $1700 \mathrm{~h}$ ) for 2 succeeding days; Oramin; Amineh Gostar Animal Health ${ }^{+}$Co.], ampicillin so- 
dium $(3 \mathrm{~mL} / \mathrm{d}$ per calf for 3 succeeding days; Ampixill; Jaber Ebne Hayyan Pharmaceutical Co.), enrofloxacin $(10 \% ; 3 \mathrm{~mL} / \mathrm{d}$ per calf for 3 succeeding days; Bristol Pharmaceutical Ltd.), and a single dose vitamin $\mathrm{AD}_{3} \mathrm{E}$ (containing 50,000 IU of vitamin A, 10,000 IU of vitamin $\mathrm{D}_{3}$, and $20 \mathrm{mg}$ of vitamin $\mathrm{E}$ per $\mathrm{mL} ; 3 \mathrm{~mL} /$ calf on d 3 of treatment protocol; ADVit; Razak Laboratories Co.) or vitamin $\mathrm{AD}_{3} \mathrm{E}(3 \mathrm{~mL} /$ calf on $\mathrm{d} 4$ of treatment protocol; ADVit; Razak Laboratories Co.) $+\mathrm{B}_{12}-\mathrm{P}$ complex (containing $0.05 \mathrm{mg}$ of cyanocobalamin and $125 \mathrm{mg}$ of sodium- $\alpha$-oxybenzylphosphinicom per $\mathrm{mL}$; $3 \mathrm{~mL} /$ calf on d 4 of treatment protocol; CobaPhos; Razak Laboratories Co.) injection. Nonresponding animals received intravenous liquid therapy using sodium chloride solution $(9 \% ; 1-2 \mathrm{~L} /$ calf; Iran Pharmaceutical Products Co.) and sugar and salt solution (dextrose $3.33 \%$ + sodium chloride 0.30\%; 1 L/calf; Shahid Ghazi Pharmaceutical Co.) with a single dose of vitamin K (containing $100 \mathrm{mg}$ of menadione sodium bisulfite/mL; $4 \mathrm{~mL} /$ calf; MenadioVit; Nasr Pharmaceutical Co.) injection when blood was seen in feces.

To treat pneumonia, the calves were administered with gentamicin (containing $50 \mathrm{mg}$ of gentamicin/mL; $3 \mathrm{~mL} / \mathrm{d}$ per calf for 4 succeeding days; Gentamicin $5 \%$; Razak Laboratories Co.), vitamin $\mathrm{AD}_{3} \mathrm{E}(3 \mathrm{~mL} / \mathrm{d}$ per calf for 4 succeeding days; ADVit; Razak Laboratories Co.), widespread antibiotic (containing 3 MIU penicillin $\mathrm{G}$ procaine $+3 \mathrm{~g}$ dihydrostreptomycin sulfate per vial; $3 \mathrm{~mL} / \mathrm{d}$ for 4 succeeding days; Stropen $3+3$; Nasr Pharmaceutical Co.), and oxytetracycline (containing $100 \mathrm{mg}$ of oxytetracycline per $\mathrm{mL} ; 3 \mathrm{~mL} / \mathrm{d}$ per calf for 4 succeeding days; OxyVet 10\%; Razak Laboratories Co.). Nonresponding animals were treated for more $4 \mathrm{~d}$ with enrofloxacin (10\%; $3 \mathrm{~mL} / \mathrm{d}$ per calf; Bristol Pharmaceutical Ltd.), widespread antibiotic (containing 50 $\mathrm{mg}$ of lincomycin hydrochloride $+100 \mathrm{mg}$ spectinomycin sulfate per $\mathrm{mL} ; 3 \mathrm{~mL} / \mathrm{d}$ per calf; Lincopec; Razak Laboratories Co.), and vitamin B-complex (containing $11 \mathrm{mg}$ of thiamin hydrochloride, $4 \mathrm{mg}$ of riboflavin sodium phosphate, $4 \mathrm{mg}$ of pyridoxine hydrochloride, 50 $\mathrm{mg}$ of nicotinamide, $2 \mathrm{mg}$ of D-panthenol, and $10 \mu \mathrm{g}$ of cyanocobalamin; $3 \mathrm{~mL} / \mathrm{d}$ per calf; Beplex; Nasr Pharmaceutical Co.). Additional treatment protocol (for an additional $3 \mathrm{~d}$ ) was applied for calves not responding to 2 first protocols. Calves were treated with meloxicam (containing $20 \mathrm{mg}$ of meloxicam/mL; $3 \mathrm{~mL} / \mathrm{d}$ per calf; MeloxiVet 2\%; Razak Laboratories Co.) and ceftriaxone (containing 1,000 mg of ceftriaxone sodium per vial; Ceftriana; Daanapharma Co.). The number of calves with treated pneumonia during the first month of the study were 8, 2, and 1 in FSP0 group, 6, 3, and 3 in FSP1.5 group, and 6,0 , and 0 in FSP3 group by treatment protocols 1 to 3 , respectively. For the rest of the study, the number of treated calves was 8,7 , and 4 for
FSP0, 9, 6, and 2 for FSP1.5, and 7, 6, and 2 for FSP3 groups. Calves experiencing pneumonia for the first time in the second month of age, received treatment protocols 1 to 3 as required. The calves with treatment history (for example protocol 1) which showed new signs of pneumonia, starting the second month of life, received another protocol (protocol 2 or 3 as required). There was at least one day between treatment protocols after which the calf was attended by the veterinarian to confirm treatment adequacy or the need for further treatment using the next protocol.

\section{Statistical Analyses}

A prestudy power analysis (POWER PROC; SAS, version 9.4; SAS Institute Inc.) for sample size assessment was carried out for the primary response variables, including weight gain and skeletal growth according to recent published literature (Saeedi et al., 2017; Hajalizadeh et al., 2019; Kargar et al., 2020). The predicted sample size was 12 calves per treatment group for variables related to growth performance $(\alpha$ $=0.05$ and power $=0.85)$. Therefore, 48 animals were considered sufficient to get a significant result with adequate power in performance among the treatment groups. To the best of our knowledge, no study has addressed the potential of FSP in reducing the incidence of diarrhea or pneumonia in dairy calves. Because there were no available data on true herd diarrhea or pneumonia incidence; we did not perform a power test for the health events before the initiation of study; however, maximum number of calves were used based on the potential available pens on the farm.

Data on ADG were subjected to ANOVA using the MIXED procedure of SAS with times (1-d period) as repeated measures. Calf was considered as a random effect, treatment ( $\mathrm{T}$; the dose response to FSP at 0 , 1.5, and $3 \mathrm{~g} / \mathrm{d}$ ), sex ( $\mathrm{S}$; female vs. male), period (P; 1-d period), $\mathrm{T} \times \mathrm{S}, \mathrm{T} \times \mathrm{P}, \mathrm{S} \times \mathrm{P}$, and $\mathrm{T} \times \mathrm{S} \times \mathrm{P}$ as fixed effects. Calves with diarrhea $(\geq 3)$, pneumonia, or both, were considered sick; this dichotomous variable (sick or not sick during the study) was also included in the model but was not significant and excluded from the final analysis. Data on initial BW and initial skeletal measurements and gains were analyzed using the same model without the period effect. Initial BW and initial skeletal measurements were used as the covariates for BW and skeletal size analysis, respectively. The autoregressive covariance structure (type 1) was the best fit for these data as determined by the lowest value for the Bayesian information criterion. Data were reported as the least squares means, and considered significant if $P \leq 0.05$ and tendency if $0.05<P \leq 0.10$. When the interaction between treatment, sex, and period was 
significant, the SLICE option in the LSMEANS statement was used to determine the differences among the factors.

Models for the occurrence of elevated rectal temperature $\left(\geq 39.4^{\circ} \mathrm{C}\right)$, diarrhea $(\geq 3)$, pneumonia, and the need for medication were evaluated during the experiment ( 1 to 81 ) by logistic regression using a binomial distribution in the GLIMMIX procedure. The odds ratio was used to compare the likelihood for calves on each treatment group to experience any event. Number of days with elevated rectal temperature $\left(\geq 39.4^{\circ} \mathrm{C}\right)$, frequency and duration of diarrhea $(\geq 3)$ or pneumonia, and administration of medication were evaluated with a Poisson distribution using the GENMOD procedure. No data were deposited in an official repository.

\section{RESULTS}

\section{Growth}

Average daily gain $(P=0.01)$, final BW $(P=0.04)$, and weight gain $(P=0.04)$ were greater in FSP-supplemented calves than in control calves (Table 2). Initial BW was greater $(P=0.02)$ in male versus female calves; however, growth rate $(P=0.97)$, final $\mathrm{BW}(P=0.86)$, and BW gain $(P=0.86)$ were not affected by calf sex. Skeletal measurements including the withers height $(P$ $=0.80)$, body length $(P=0.58)$, and hip height $(P=$ $0.78)$ were not affected by treatment. Final heart girth and its gain were greater $(P=0.02)$ and tended $(P$ $\leq 0.10)$ to be greater in FSP3 and FSP1.5 relative to FSP0, respectively. Final hip width and its gain were greater $(P=0.02)$ in FSP-supplemented calves than in not-supplemented calves. Initial skeletal measurements including the heart girth $(P=0.03)$, withers height $(P$ $=0.01)$, body length $(P=0.01)$, and hip height $(P \leq$ $0.01)$, but not hip width $(P=0.28)$, were greater in male versus female calves; however, frame growth was not affected $(P \geq 0.13)$ by the calf sex.

\section{Health}

Table 3 shows the logistic models for the occurrence of elevated rectal temperature $\left(\geq 39.4^{\circ} \mathrm{C}\right)$, diarrhea $(\geq 3)$, pneumonia, and the need for medication. The occurrence of elevated rectal temperature was greater in control calves compared with FSP-supplemented calves $[($ FSP1.5 odds ratio $=1.35 ; P=0.04)$ or (FSP3 odds ratio $=1.74 ; P=0.001)]$. Control calves had greater chance of diarrhea $[($ FSP1.5 odds ratio $=1.52 ; P=$ $0.001)$ or (FSP3 odds ratio $=1.42 ; P=0.003)]$ and pneumonia $[(\mathrm{FSP} 1.5$ odds ratio $=1.61 ; P=0.001)$ or (FSP3 odds ratio $=1.62 ; P=0.001)]$ compared with FSP-supplemented calves. The chance of medication for diarrhea $(P \geq 0.64)$ or pneumonia $(P \geq 0.60)$ was not different among treatment groups. Female calves had greater chance of diarrhea (odds ratio $=1.26 ; P=$ 0.01 ) but not pneumonia (odds ratio $=1.04 ; P=0.65$ ) or elevated rectal temperature (odds ratio $=0.84 ; P=$ 0.18 ) compared with male calves with no difference in the chance of medication for diseases $(P \geq 0.30)$. No incidence of diarrhea was observed after $30 \mathrm{~d}$ of age.

Table 4 shows the Poisson regression for days medicated, days with elevated rectal temperature $\left(\geq 39.4^{\circ} \mathrm{C}\right)$, and frequency and duration of diarrhea $(\geq 3)$ or pneumonia during the study period. Days with elevated rectal temperature were greater in control calves compared with FSP1.5 (1.7 d; SEM $=0.10 ; P=0.003)$ and FSP3 (2.9 d; SEM $=0.10 ; P=0.003)$ calves. It was also greater in FSP1.5 calves than those fed FSP3 $(1.2 \mathrm{~d} ; \mathrm{SEM}=0.10 ; P=0.003)$. Days with diarrhea were shorter in FSP-supplemented calves than those not-supplemented (4 d; SEM $=0.10 ; P=0.001$ ); however, the frequency and medication days for diarrhea were not affected by treatment $(P \geq 0.32)$. Days with pneumonia were greater in control calves than those fed FSP1.5 (3.1 d; SEM $=0.08 ; P=0.001)$ and FSP3 $(5.4 \mathrm{~d} ; \mathrm{SEM}=0.08 ; P=0.001)$; it was also greater in FSP1.5 vs. FSP3 calves $(2.3 \mathrm{~d}$; SEM $=0.08 ; P=$ $0.001)$. Medication days for pneumonia tended to be greater $(1.6 \mathrm{~d}$; $\mathrm{SEM}=0.10 ; P=0.09)$ in control calves than those fed FSP; however, the frequency of pneumonia was not affected by treatment. Female calves experienced longer days with diarrhea $(2.2 \mathrm{~d}$; SEM $=$ $0.10 ; P=0.02)$ and medication duration $(1.3 \mathrm{~d}$; SEM $=0.15 ; P=0.03)$. Calf sex did not affect the number of days with elevated rectal temperature and pneumonia.

\section{DISCUSSION}

\section{Growth}

The higher BW, ADG, and skeletal growth (especially heart girth and hip width) in FSP-supplemented calves may, in part, be attributed to increased feed intake and stimulated by the estrogenic compounds (e.g., trans-anethole, flavonoids, and diosgenin; Kooti et al., 2015) in fennel seeds. Fennel seed powder used in the present study, contained $1.6 \%$ essential oil with $76.7 \%$ trans-anethole, $\sim 9.8 \%$ fenchone, and $\sim 3.2 \%$ estragole (data not shown), which have appetite-stimulatory effects (Saeedi et al., 2017; Hajalizadeh et al., 2019; Kargar et al., 2021). More recently, Kargar et al. (2021), in a companion study, showed that feeding FSP to Holstein calves increased the sensory perception of feed by decreasing the time to initiate the first meal after morning feeding and increasing the starter feed intake through increased eating rate and meal size. It is 


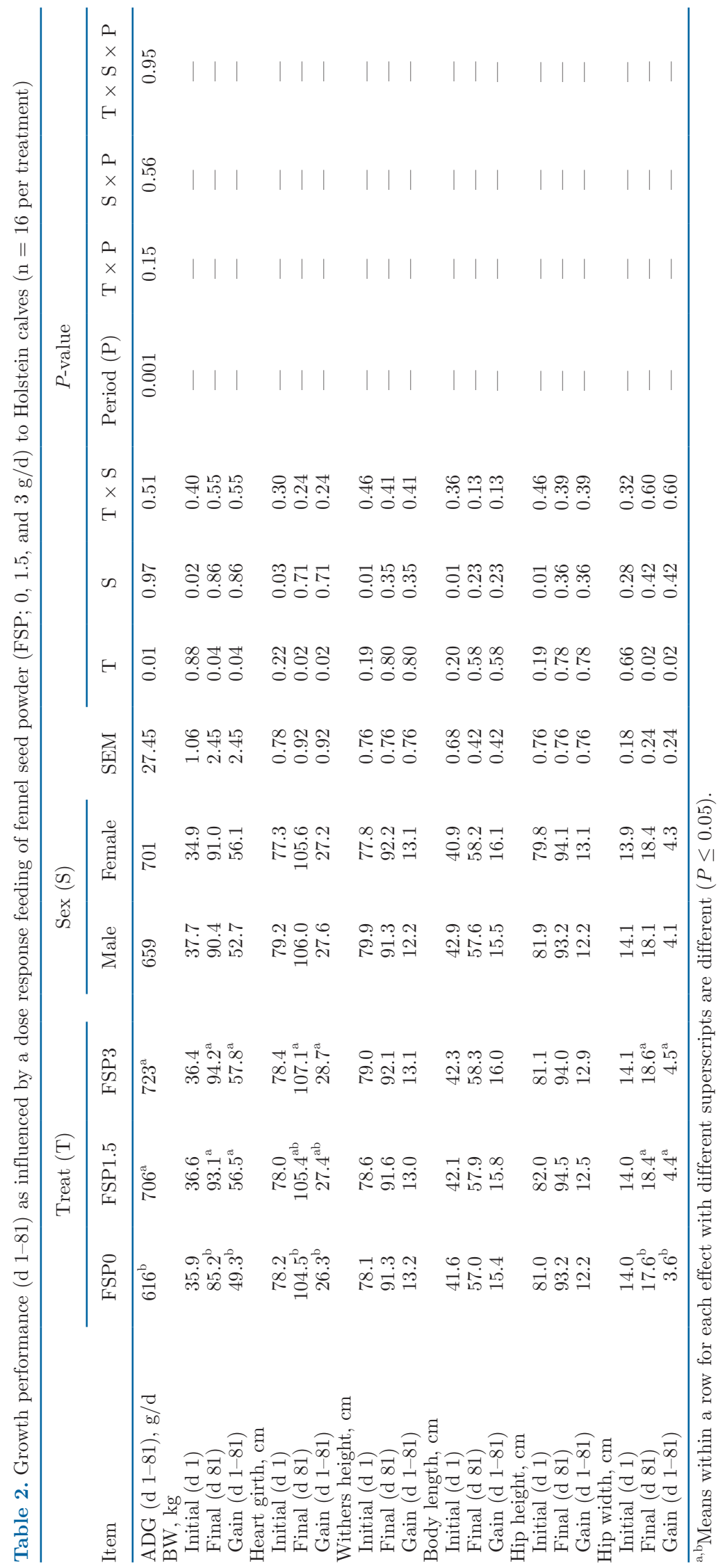


Table 3. Logistic model for elevated rectal temperature $\left(\geq 39.4^{\circ} \mathrm{C}\right)$, diarrhea $(\geq 3),{ }^{1}$ pneumonia, and medication occurrence during the experiment (d 1-81) as influenced by feeding the dose response of fennel seed powder (FSP; $0,1.5$, and $3 \mathrm{~g} / \mathrm{d}$ ) to Holstein calves ( $\mathrm{n}=16$ per treatment)

\begin{tabular}{|c|c|c|c|c|c|}
\hline Variable and comparison & Coefficient & SEM & $\mathrm{OR}^{2}$ & $95 \% \mathrm{CI}$ & $P$-value \\
\hline \multicolumn{6}{|l|}{ Rectal temperature } \\
\hline FSP0 vs. FSP1.5 & 0.3028 & 0.14 & 1.35 & $1.01,1.80$ & 0.04 \\
\hline FSP0 vs. FSP3 & 0.5561 & 0.16 & 1.74 & $1.26,2.40$ & 0.001 \\
\hline FSP1.5 vs. FSP3 & 0.2534 & 0.17 & 1.28 & $0.91,1.80$ & 0.14 \\
\hline Female vs. male & -0.1747 & 0.13 & 0.84 & $0.65,1.08$ & 0.18 \\
\hline \multicolumn{6}{|l|}{ Diarrhea occurrence } \\
\hline FSP0 vs. FSP1.5 & 0.4190 & 0.11 & 1.52 & $1.21,1.90$ & 0.001 \\
\hline FSP0 vs. FSP3 & 0.3505 & 0.11 & 1.42 & $1.12,1.79$ & 0.003 \\
\hline FSP1.5 vs. FSP3 & -0.0684 & 0.12 & 0.93 & $0.72,1.19$ & 0.58 \\
\hline Female vs. male & 0.2364 & 0.09 & 1.26 & $1.04,1.53$ & 0.01 \\
\hline \multicolumn{6}{|c|}{ Diarrhea medication occurrence } \\
\hline FSP0 vs. FSP1.5 & -0.0854 & 0.18 & 0.91 & $0.63,1.31$ & 0.64 \\
\hline FSP0 vs. FSP3 & -0.0204 & 0.19 & 0.98 & $0.67,1.42$ & 0.91 \\
\hline FSP1.5 vs. FSP3 & 0.0650 & 0.19 & 1.06 & $0.72,1.56$ & 0.74 \\
\hline Female vs. male & -0.0331 & 0.15 & 0.71 & $0.52,0.97$ & 0.30 \\
\hline \multicolumn{6}{|l|}{ Pneumonia occurrence } \\
\hline FSP0 vs. FSP1.5 & 0.4800 & 0.11 & 1.61 & $1.27,2.04$ & 0.001 \\
\hline FSP0 vs. FSP3 & 0.4836 & 0.12 & 1.62 & $1.27,2.07$ & 0.001 \\
\hline FSP1.5 vs. FSP 3 & 0.0036 & 0.13 & 1.00 & $0.77,1.30$ & 0.97 \\
\hline Female vs. male & 0.0455 & 0.10 & 1.04 & $0.85,1.27$ & 0.65 \\
\hline \multicolumn{6}{|c|}{ Pneumonia medication occurrence } \\
\hline FSP0 vs. FSP1.5 & -0.0712 & 0.14 & 0.96 & $0.57,1.01$ & 0.60 \\
\hline FSP0 vs. FSP3 & -0.0702 & 0.15 & 0.96 & $0.56,1.03$ & 0.71 \\
\hline FSP1.5 vs. FSP3 & 0.0000 & 0.16 & 1.00 & $0.72,1.37$ & 1.00 \\
\hline Female vs. male & 0.0226 & 0.12 & 1.02 & $0.80,1.30$ & 0.85 \\
\hline
\end{tabular}

${ }^{1} 1=$ normal; $2=$ soft to loose; $3=$ loose to watery; $4=$ watery, mucous, and slightly bloody; $5=$ watery, mucous, and bloody (Heinrichs et al., 2003). No diarrhea incidence was captured starting the second month of calf age.

${ }^{2}$ The odds ratio $(\mathrm{OR})$ indicates the probability of having elevated rectal temperature $\left(\geq 39.4^{\circ} \mathrm{C}\right)$, diarrhea $(\geq 3)$, or pneumonia, or needing medication for the experimental diets (FSP0 vs. FSP1.5; FSP0 vs. FSP3; and FSP1.5 vs. FSP3). If the OR is $>1$, a given diet in the comparison is more likely to have elevated rectal temperature, diarrhea, or pneumonia or to be medicated than the other diet by a factor of the difference above 1 . If the OR is $<1$, a given diet has a lower probability of occurrence than the other diet.

well-documented that trans-anethole, as the main component of the fennel seed essential oil (Kargar et al., 2021), contains estrogenic activity (Albert-Puleo, 1980; Badgujar et al., 2014; Kooti et al., 2015). Estrogenic compounds, as anabolic agents, positively affect skeletal muscle and bone growth (Sauerwein and Meyer, 1989; Notelovitz, 2002; Velders et al., 2012), increase glucose entry to muscle cells (Mauvais-Jarvis et al., 2013), activate the satellite cells (Johnson et al., 1998; Velders et al., 2012; Forcina et al., 2019), modulate the immune

Table 4. Poisson regression for days with elevated rectal temperature $\left(\geq 39.4^{\circ} \mathrm{C}\right)$, frequency and duration of diarrhea $(\geq 3),{ }^{1}$ pneumonia, and days medicated during the experimental period (d 1-81) as influenced by the dose response feeding of fennel seed powder (FSP; 0, 1.5, and 3 $\mathrm{g} / \mathrm{d})$ to Holstein calves $(\mathrm{n}=16$ per treatment)

\begin{tabular}{|c|c|c|c|c|c|c|c|c|}
\hline Item & \multicolumn{3}{|c|}{ Treatment } & \multicolumn{2}{|c|}{ Sex } & SEM & \multicolumn{2}{|c|}{$P$-value } \\
\hline $\begin{array}{l}\text { Days with elevated rectal temperature }(\geq 39.4) \\
\text { Diarrhea }\end{array}$ & $7.2^{\mathrm{a}}$ & $5.5^{\mathrm{b}}$ & $4.3^{\mathrm{c}}$ & 6.2 & 5.1 & 0.10 & 0.003 & 0.15 \\
\hline Frequency, no. of times diagnosed & 3.1 & 2.3 & 2.8 & 2.6 & 2.9 & 0.36 & 0.32 & 0.49 \\
\hline Duration, d & $13.7^{\mathrm{a}}$ & $9.6^{\mathrm{b}}$ & $9.8^{\mathrm{b}}$ & 10.2 & 12.4 & 0.10 & 0.001 & 0.02 \\
\hline Medication, d & 4.0 & 3.7 & 3.9 & 3.3 & 4.6 & 0.15 & 0.89 & 0.03 \\
\hline Duration, d & $12.6^{\mathrm{a}}$ & $9.5^{\mathrm{b}}$ & $7.2^{\mathrm{c}}$ & 9.7 & 10.0 & 0.08 & 0.001 & 0.67 \\
\hline Medication, d & 7.1 & 5.5 & 5.5 & 6.1 & 6.0 & 0.10 & 0.09 & 0.86 \\
\hline
\end{tabular}

${ }^{\mathrm{a}-\mathrm{c}}$ Means within a row with different superscripts are different $(P \leq 0.05)$.

${ }^{1} 1=$ normal; $2=$ soft to loose; $3=$ loose to watery; $4=$ watery, mucous, and slightly bloody; 5 = watery, mucous, and bloody (Heinrichs et al., 2003). No diarrhea incidence was captured starting the second month of calf age. 
responses, and are anti-inflammatory (Chilibeck and Cornish, 2008; Velders et al., 2012). Adding 0.4 and $0.8 \%$ (DM basis) FSP to the starter feed diets increased the BW gain in Holstein calves (Saeedi et al., 2017) without affecting the skeletal growth measured $2 \mathrm{wk}$ after weaning (Saeedi et al., 2016); this lack of response may be due to different ages at which the skeletal size was measured because the study was primarily designed to evaluate the effect of FSP on the weaning age (calves were weaned when they consumed $1 \mathrm{~kg}$ of starter feed for 3 consecutive days). Therefore, FSP-supplemented versus not-supplemented calves were younger $(\sim 18 \mathrm{~d})$ at weaning. Final BW and growth rate also increased when FSP was added at 0.75 and $1.50 \%$ (DM basis) to the diets of fattening lambs (Hajalizadeh et al., 2019).

\section{Health}

The positive effect of FSP on the calf health (Tables 3 and 4) might be attributed to several bioactive compounds in fennel (Soltan, 2009; Kooti et al., 2015; Hajalizadeh et al., 2019). Our findings, in terms of fecal consistency are not consistent with Saeedi et al. (2016, 2017), who fed higher levels of FSP (at 0.4 and $0.8 \%$ in the starter feed DM) to calves. Fennel has been reported to be effective in treatment of several gastrointestinal (including diarrhea, bloat, and colic) and respiratory (including coughing and bronchitis) disturbances (Badgujar et al., 2014; Kooti et al., 2015); however, high levels of herbal plants or their derivatives may predispose animals to diarrhea or higher fecal score which is linked to considerable decrease in gut microbial population and abnormal microbial activity (Soltan, 2009). For comparative purposes, we could not find any published report addressing the effect of FSP on the calf health and well-being.

The reason(s) for higher susceptibility to diarrhea, longer days with diarrhea, and longer duration of veterinary treatment in female versus male calves during the first month of age is unclear and needs further investigation. All calves had successful and adequate passive transfer of immunity, and were healthy as examined by the herd veterinarian when enrolled in the study. However, the recorded differences in health events did not affect the weight gain and frame growth between female and male calves.

As the present study was performed in a commercial dairy farm, the farm-produced waste milk was fed in lieu of milk replacer due to high availability and lower cost. Although feeding milk replacer could potentially alleviate the day-to-day variations in its contents, the daily variations in the composition of waste milk would have similar effect on the performance, because calves in all treatment groups received their milk portion from a single pooled source. A restrictive milk allowance to calves in the present study might have affected the feeding behavior and growth performance. Calves fed lower milk rations may be more likely to experience the poor-welfare effects of prolonged hunger and show increased behavioral symptoms of hunger, including a higher number of vocalizations at 5 wk of age (Thomas et al., 2001) and unrewarded visits to the milk feeder before and during weaning (Rosenberger et al., 2017). Calves fed more milk grew faster before weaning than those fed restricted milk (Rosenberger et al., 2017) if step-down weaning technique (Mirzaei et al., 2020) or social housing strategy were implemented (Costa et al., 2015; Jensen et al., 2015). However, a recent survey indicated that $53 \%$ of farms in the United States provided the dairy heifer calves with only 4 to $5 \mathrm{~L}$ of milk/d (USDA, 2016). Calves fed lower milk rations may strive to compensate with increased intake of the starter feed, especially after 4 wk of age (Khan et al., 2007). Increased familiarity with starter feed (especially the starters containing flavoring agents) before weaning may be helpful in improved transition from milk to solid feed at weaning; therefore, lesser milk feeding before weaning may reduce the postweaning stress and growth check.

\section{CONCLUSIONS}

Our findings showed that feeding FSP (especially at the level of $3 \mathrm{~g} / \mathrm{d}$ ) before weaning had the potential to increase the BW gain and skeletal growth (heart girth and hip width) in dairy calves. This was likely due to increased feed intake, decreased susceptibility to diarrhea and pneumonia, and fewer days with elevated rectal temperature, diarrhea, or pneumonia. During the first month of life, female calves experienced higher susceptibility to diarrhea and longer duration and medication days compared with the male calves with no differences in overall performance. Considering the growing concern and objections to the use of conventional antibiotics in animals, the findings of the present work, as well as those of other published works, show that the use of medicinal plants or their derivatives - as natural antimicrobial agents - may be used as a new strategy in maintaining the health and welfare of animals and humans as the consumers of animal products. Further experiments are needed to determine the molecular mechanism(s) involved in the positive effects of such feed additives on calf growth and health.

\section{ACKNOWLEDGMENTS}

The first author (S. Kargar) was the grant identifier and this research was supported by Shiraz University 
(Shiraz, Iran) and Pegah-e-Fars Agriculture and Animal Husbandry (Shiraz, Iran). Authors thank Shiraz University and Pegah-e-Fars Agriculture and Animal Husbandry Farm for partial funding of research, providing suitable trial conditions, and for diligent animal care. The authors have not stated any conflicts of interest.

\section{REFERENCES}

Al-Sagan, A. A., S. Khalil, E. O. S. Hussein, and Y. A. Attia. 2020. Effects of fennel seed powder supplementation on growth performance, carcass characteristics, meat quality, and economic efficiency of broilers under thermoneutral and chronic heat stress conditions. Animals (Basel) 10:206.

Albert-Puleo, M. 1980. Fennel and anise as estrogenic agents. J. Ethnopharmacol. 2:337-344. https://doi.org/10.1016/S0378 -8741(80)81015-4.

AOAC International. 2002. Official Methods of Analysis. 17th ed. AOAC International.

Badgujar, S. B., V. V. Patel, and A. H. Bandivdekar. 2014. Foeniculum vulgare Mill: A review of its botany, phytochemistry, pharmacology, contemporary application, and toxicology. BioMed Res. Int. 2014:842674. https://doi.org/10.1155/2014/842674.

Chilibeck, P. D., and S. M. Cornish. 2008. Effect of estrogenic compounds (estrogen or phytoestrogens) combined with exercise on bone and muscle mass in older individuals. Appl. Physiol. Nutr. Metab. 33:200-212. https://doi.org/10.1139/H07-140.

Costa, J. H. C., R. K. Meagher, M. A. G. von Keyserlingk, and D. M. Weary. 2015. Early pair housing increases solid feed intake and weight gains in dairy calves. J. Dairy Sci. 98:6381-6386. https:// doi.org/10.3168/jds.2015-9395.

Dairy Calf and Heifer Association. 2010. Gold Standards. Accessed Sep. 30, 2021. https://calfandheifer.org/gold-standards/.

Forcina, L., C. Miano, L. Pelosi, and A. Musarò. 2019. An overview about the biology of skeletal muscle satellite cells. Curr. Genomics 20:24-37. https://doi.org/10.2174/1389202920666190116094736.

Hajalizadeh, Z., O. Dayani, A. Khezri, R. Tahmasbi, and M. R. Mohammadabadi. 2019. The effect of adding fennel (Foeniculum vulgare) seed powder to the diet of fattening lambs on performance, carcass characteristics and liver enzymes. Small Rumin. Res. 175:72-77. https://doi.org/10.1016/j.smallrumres.2019.04.011.

Heinrichs, A. J., C. M. Jones, L. R. VanRoekel, and M. A. Fowler 2003. Calf Track: A system of dairy calf workforce management, training, and evaluation and health evaluation. J. Dairy Sci. 86(Suppl. 1):115. (Abstr.)

Iranian Council of Animal Care. 1995. Guide for the Care and Use of Experimental Animals, Vol. 1. Isfahan University of Technology.

Jensen, M. B., L. R. Duve, and D. M. Weary. 2015. Pair housing and enhanced milk allowance increase play behavior and improve performance in dairy calves. J. Dairy Sci. 98:2568-2575. https://doi .org $/ 10.3168 /$ jds. 2014-8272.

Johnson, B. J., N. Halstead, M. E. White, M. R. Hathaway, A. DiCostanzo, and W. R. Dayton. 1998. Activation state of muscle satellite cells isolated from steers implanted with a combined trenbolone acetate and estrodiol implant. J. Anim. Sci. 76:2779-2786. https://doi.org/10.2527/1998.76112779x.

Kargar, S., and M. Kanani. 2019. Reconstituted versus dry alfalfa hay in starter feed diets of Holstein dairy calves: Effects on growth performance, nutrient digestibility, and metabolic indications of rumen development. J. Dairy Sci. 102:4051-4060. https://doi.org/ $10.3168 /$ jds.2018-15153.

Kargar, S., F. Nowroozinia, and M. Kanani. 2021. Feeding fennel (Foeniculum vulgare) seed as potential appetite stimulant to newborn Holstein dairy calves: Effects on meal pattern, ingestive behavior, oro-sensorial preference, and feed sorting. Anim. Feed Sci. Technol. 278:115009. https://doi.org/10.1016/j.anifeedsci.2021.115009.
Kargar, S., M. Roshan, S. M. Ghoreishi, A. Akhlaghi, M. Kanani, A. R. Abedi-Shams-Abadi, and M. H. Ghaffari. 2020. Extended colostrum feeding for two weeks improves growth performance and reduces the susceptibility to diarrhea and pneumonia in neonatal Holstein dairy calves. J. Dairy Sci. 103:8130-8142. https://doi .org/10.3168/jds.2020-18355.

Khan, M. A., H. J. Lee, W. S. Lee, H. S. Kim, S. B. Kim, K. S. Ki, J. K. Ha, H. G. Lee, and Y. J. Choi. 2007. Pre- and postweaning performance of Holstein female calves fed milk through step-down and conventional methods. J. Dairy Sci. 90:876-885. https://doi .org/10.3168/jds.S0022-0302(07)71571-0.

Kooti, W., M. Moradi, S. Ali-Akbari, N. Sharafi-Ahvazi, M. AsadiSamani, and D. Ashtary-Larky. 2015. Therapeutic and pharmacological potential of Foeniculum vulgare Mill: A review. J. Herbmed Pharmacol. 4:1-9.

Larson, L. L., F. G. Owen, J. L. Albright, R. D. Appleman, R. C. Lamb, and L. D. Muller. 1977. Guidelines toward more uniformity in measuring and reporting calf experimental data. J. Dairy Sci. 60:989-991. https://doi.org/10.3168/jds.S0022-0302(77)83975-1.

Mauvais-Jarvis, F. D. J. Clegg, and A. L. Hevener. 2013. The role of estrogens in control of energy balance and glucose homeostasis. Endocr. Rev. 34:309-338. https://doi.org/10.1210/er.2012-1055.

McGuirk, S. M., and S. F. Peek. 2014. Timely diagnosis of dairy calf respiratory disease using a standardized scoring system. Anim. Health Res. Rev. 15:145-147. https://doi.org/10.1017/ S1466252314000267.

Mirzaei, M., H. Khanaki, M. Kazemi-Bonchenari, M. A. Khan. A. H. Khaltabadi-Farahani, M. Hossein-Yazdi, and M. H. Ghaffari. 2020. Effects of step-down weaning implementation time on growth performance and blood metabolites of dairy calves. J. Dairy Sci. 103:10099-10107. https://doi.org/10.3168/jds.2020-18520.

Murray-Kerr, C. F., K. E. Leslie, S. M. Godden, W. A. Knauer, and S. M. McGuirk. 2018. Development of a newborn calf vigor scoring system. Proceedings of the 51st Annual Conference, American Assoc. Bovine Pract. 283. BM Publishing Co.

Notelovitz, M. 2002. Androgen effects on bone and muscle. Fertil. Steril. 77(Suppl. 4):34-S1. https://doi.org/10.1016/S0015 -0282(02)02968-0.

NRC. 2001. Nutrient Requirements of Dairy Cattle. 7th rev. ed. Natl. Acad. Sci.

Pardon, B., K. De Bleecker, M. Hostens, J. Callens, J. Dewulf, and P. Deprez. 2012. Longitudinal study on morbidity and mortality in white veal calves in Belgium. BMC Vet. Res. 8:26. https://doi.org/ 10.1186/1746-6148-8-26.

Pempek, J., D. Trearchis, M. Masterson, G. Habing, and K. Proudfoot. 2017. Veal calf health on the day of arrival at growers in Ohio. J. Anim. Sci. 95:3863-3872. https://doi.org/10.2527/jas2017 .1642 .

Renaud, D. L., D. F. Kelton, S. J. LeBlanc, D. B. Haley, and T. F. Duffield. 2018. Calf management risk factors on dairy farms associated with male calf mortality on veal farms. J. Dairy Sci. 101:1785-1794. https://doi.org/10.3168/jds.2017-13578.

Rosenberger, K., J. H. C. Costa, H. W. Neave, M. A. G. von-Keyserlingk, and D. M. Weary. 2017. The effect of milk allowance on behavior and weight gains in dairy calves. J. Dairy Sci. 100:504-512. https://doi.org/10.3168/jds.2016-11195.

Saeedi, S., O. Dayani, A. Khezri, and R. Tahmasbi. 2016. The effect of using fennel powder in starter diets on performance, immunity system and biometric parameters of Holstein calves. Iran. J. Anim. Sci. 46:371-378.

Saeedi, S., O. Dayani, R. Tahmasbi, and A. Khezri. 2017. Effect of supplementation of calf starter with fennel powder on performance, weaning age and fermentation characteristics in Holstein dairy calves. J. Anim. Physiol. Anim. Nutr. (Berl.) 101:81-87. https://doi.org/10.1111/jpn.12511.

Sauerwein, H., and H. H. D. Meyer. 1989. Androgen and estrogen receptors in bovine skeletal muscle: Relation to steroid-induced allometric muscle growth. J. Anim. Sci. 67:206-212. https://doi.org/ 10.2527/jas1989.671206x.

Scott, K., D. F. Kelton, T. F. Duffield, and D. L. Renaud. 2019. Risk factors identified on arrival associated with morbidity and mortali- 
ty at a grain-fed veal facility: A prospective, single-cohort study. J. Dairy Sci. 102:9224-9235. https://doi.org/10.3168/jds.2019-16829.

Soltan, M. A. 2009. Effect of essential oils supplementation on growth performance, nutrient digestibility, health condition of Holstein male calves during pre- and post-weaning periods. Pak. J. Nutr. 8:642-652. https://doi.org/10.3923/pjn.2009.642.652.

Thomas, T. J., D. M. Weary, and M. C. Appleby. 2001. Newborn and 5 -week old calves vocalize in response to milk deprivation. Appl. Anim. Behav. Sci. 74:165-173. https://doi.org/10.1016/S0168 -1591(01)00164-2.

Urie, N. J., J. E. Lombard, C. B. Shivley, C. A. Kopral, A. E. Adams, T. J. Earleywine, J. D. Olson, and F. B. Garry. 2018. Preweaned heifer management on US dairy operations: Part V. Factors associated with morbidity and mortality in preweaned dairy heifer calves. J. Dairy Sci. 101:9229-9244. https://doi.org/10.3168/jds .2017-14019.

USDA. 2016. Dairy 2014: Dairy Cattle Management Practices in the United States, 2014. NAHMS \#692.0216. USDA, Animal and Plant Health Inspection Service (APHIS), Veterinary Services (VS), Center for Epidemiology and Health (CEAH).

Van Soest, P. J., J. B. Robertson, and B. A. Lewis. 1991. Methods for dietary fiber, neutral detergent fiber, and nonstarch polysaccharides in relation to animal nutrition. J. Dairy Sci. 74:3583-3597.
Velders, M., B. Schleipen, K. H. Fritzemeier, O. Zierau, and P. Diel. 2012. Selective estrogen receptor- $\beta$ activation stimulates skeletal muscle growth and regeneration. FASEB J. 26:1909-1920. https:/ /doi.org/10.1096/fj.11-194779.

Yari-Haj-Atalou, M., R. Pirmohammadi, H. Khalilvandi-Behroozyar, and Y. Alijoo. 2017. Effects of fennel seed (Foeniculum vulgare) powder in corn or barley grain-based diets on milk production and composition, ruminal fermentation and some blood parameters in Mohabadi dairy goats pre- and post-partum. Anim. Sci. Res. 28:141-158.

\section{ORCIDS}

F. Nowroozinia @ https://orcid.org/0000-0001-7850-5496

S. Kargar (1) https://orcid.org/0000-0003-0418-1868

A. Akhlaghi @ $\odot$ https://orcid.org/0000-0003-4679-6115

F. Raouf Fard ๑ https://orcid.org/0000-0002-3798-0191

M. Bahadori-Moghaddam ( https://orcid.org/0000-0001-5144-3555

M. Kanani ๑ https://orcid.org/0000-0002-1204-4647

M. J. Zamiri @ https://orcid.org/0000-0002-3191-5313 